\title{
La Educación Superior conceptualizada como Bien Común: El desafío propuesto por Unesco
}

\author{
Higher Education as a Concept of Common Good: The Challenge Posed by UNESCO
}

A Educação Superior conceitualizada como um bem comum: o desafio proposto pela UNESCO

Oscar Daniel Licandro* https://orcid.org/0000-0002-7771-2933

Departamento de Ciencias de la Administración, Universidad Católica del Uruguay, Montevideo - Uruguay

Sandra Lorena Yepes Chisco https://orcid.org/0000-0001-7084-6691

Vicerrectoría de Responsabilidad Social y Bienestar Universitario, Licenciatura en Etnoeducación, Universidad

Tecnológica de Pereira, Pereira - Colombia

$\nabla$

Recibido: 15/03/18 Revisado: 28/04/18 Aceptado: 28/05/18 Publicado: 30/06/18

- Resumen. El llamado de UNESCO de 2015 a conceptualizar la Educación Superior (ES) como un bien común abre las puertas a una nueva perspectiva para la comprensión y búsqueda de solución a un conjunto de problemas derivados de su creciente privatización. Este llamado, para no quedar en el discurso y producir un impacto real transformador, requiere reflexionar sobre las implicancias teóricas y prácticas de esta nueva forma de conceptualizar la ES. Se necesita construir un marco teórico y herramientas prácticas que permitan migrar de las formas actuales de gobernanza de la ES, diseñadas para gestionar un bien público, hacia las formas específicas de la gobernanza de los bienes comunes. En este documento se argumenta que el llamado de UNESCO tiene un sustento teórico sólido, para lo cual se realiza una revisión bibliográfica sobre la teoría de los bienes comunes y se demuestra que la ES califica para ser considerada como tal. Además, se reflexiona sobre los impactos que esta re-conceptualización tiene sobre la gobernanza de la ES y sobre los cambios que se necesita introducir en ella. El documento concluye sugiriendo que el marco teórico y metodológico de la Responsabilidad Social Universitaria aporta una base sobre la que edificar esos cambios.
Palabras clave:

educación

superior, bienes

comunes,

gobernanza,

responsabilidad

social

universitaria. 
Abstract. The 2015 UNESCO's call for the conceptualization of Higher Education (HE) as a common good opens doors to a new perspective for the understanding and search of a solution to a set of problems stemming from its increasing privatization. For this call not to remain as a mere speech and be able to produce a real transforming impact, it needs to reflect on the theoretical and practical implications of this new way of conceptualizing HE. A new theoretical framework and practical tools need to be built so as to migrate from the current forms of HE governance, designed to manage a public good, towards the specific forms of governance of common goods. This document discusses UNESCO's call as having a solid theoretical foundation, for which a bibliographical review on the theory of the common goods is performed, demonstrating that Higher Education can be, indeed, considered as such. This work reflects, also, on the impact of this reconceptualization on the governance of $\mathrm{HE}$ and on the changes to be introduced to it. This work concludes suggesting that the theoretical and methodological framework of University Social Responsibility contributes a base on which to build those changes.

- Resumo. A convocação da UNESCO de 2015 para conceitualizar o ensino superior como um bem comum abre as portas para uma nova perspectiva de entendimento e busca de uma solução para um conjunto de problemas decorrentes de sua crescente privatização. Esse chamado, para não permanecer no discurso e produzir um impacto transformador real, requer refletir sobre as implicações teóricas e práticas dessa nova forma de conceituar a ES. É necessário construir um arcabouço teórico e ferramentas práticas que permitam migrar das atuais formas de governança do ES, projetadas para gerir um bem público, até as formas específicas de governança dos bens comuns. Neste documento, argumenta-se que a convocação da UNESCO tem uma sólida base teórica, para a qual é feita uma revisão bibliográfica sobre a teoria dos bens comuns e é demonstrado que o ES se qualifica para ser considerada como tal. Além disso, reflete sobre os impactos que essa re-conceitualização tem sobre a governança do ES e sobre as mudanças que precisam ser introduzidas no mesmo. $\mathrm{O}$ documento conclui sugerindo que a estrutura teórica e metodológica da Responsabilidade Social Universitária fornece uma base sobre a qual construir essas mudanças.
Keywords:

higher education, common good, governance, university social responsibility.

Palavras-chave: educação superior, bens comuns, governança, responsabilidade social universitária. 


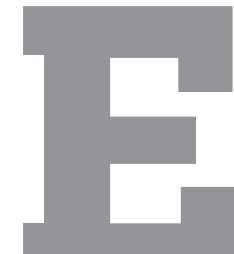

n el documento titulado Replantear la educación ¿Hacia un bien común mundial? (Unesco, 2015) propone por primera vez pasar de conceptualizar la Educación Superior como un bien público a entenderla como un bien común. La razón por la que Unesco propone hacerlo es una respuesta a la necesidad de encontrar una solución al problema de su creciente privatización. Si bien la Educación Superior privada (principalmente en universidades que responden a órdenes religiosas y asociaciones civiles) siempre existió, la importancia actual del fenómeno está dada por la "escala, alcance y penetración" con la que está ocurriendo (Unesco, 2015, p. 79).

Este llamado de Unesco, para no quedar en el discurso y producir un impacto real transformador, requiere reflexionar sobre las implicancias teóricas y prácticas de esta nueva forma de conceptualizar la ES. Se necesita construir un marco teórico y herramientas prácticas que permitan migrar de las formas actuales de gobernanza de la ES, diseñadas para gestionar un bien público, hacia las formas específicas de la gobernanza de los bienes comunes. El propósito de este documento es aportar algunas ideas que contribuyan al debate sobre este tema.

Este documento se estructura de la siguiente forma. En el primer apartado se reflexiona sobre el problema de la creciente privatización de la ES. En el segundo se presenta un breve análisis de algunos de sus problemas actuales, que alimentan o son consecuencia de los procesos privatizadores. Estos problemas, tal como se argumentará más adelante, serían factibles de abordar con mayor eficacia si se conceptualiza la ES como un bien común, que si se continúa viéndola como un bien público que gestiona el Estado o el sector privado. En el tercer apartado se abordan diversos aspectos teóricos relacionados con el concepto de bienes comunes (commons), incluyendo un análisis de los distintos bienes que abarca este concepto y algunos aspectos críticos de su gobernanza. En el cuarto apartado se aporta una fundamentación, a la luz de los conceptos analizados en el apartado anterior, de por qué es correcto y útil conceptualizar la Educación Superior como un bien común. En el quinto apartado se proponen algunas ideas acerca de cómo el marco conceptual de los bienes comunes, particularmente los principios específicos de su gobernanza, puede contribuir a la solución de los problemas que vive actualmente la Educación Superior. Finalmente, en el sexto apartado se sugiere que la teoría de la Responsabilidad Social Universitaria ya incluye, sin ser consciente de ello, un abordaje de la gobernanza y gestión universitaria en qué basar la migración hacia una Educación Superior conceptualizada como bien común.

\section{El problema de la creciente privatización de la educación superior}

Por privatización de la ES, Unesco entiende: "el proceso por el que pasan de manos del Estado o de las instituciones públicas a individuos y organismos privados las actividades, los haberes, la gestión, las funciones y las responsabilidades propias de la educación" (Unesco, 2015, p. 79). Si 
bien para Unesco esta privatización puede tener algunos efectos positivos, como la ampliación de la oferta de programas de estudios, seguramente tiene también efectos negativos como la amenaza al acceso universal al derecho a la educación, que es un derecho humano fundamental que permite la realización de los otros derechos (Unesco, 2015) y es una de las principales herramientas generadoras de igualdad de oportunidades en la sociedad contemporánea. En ese sentido, se señala que este fenómeno "podría tener un impacto negativo en el disfrute del derecho a una educación de calidad y en la puesta en marcha de igualdad de oportunidades educativas" (Unesco, 2015, p. 80). Un problema adicional de la privatización, señalado por Figueroa (2016) al referirse a la propuesta de Unesco, radica en la exclusión de los ciudadanos de los procesos de toma de decisiones sobre el uso de los bienes públicos ligados con la educación.

Kranich (2016) plantea el problema en el campo específico de la creación y difusión del conocimiento. Al respecto, señala que "muchos de los recursos académicos anteriormente disponibles a través de las bibliotecas se encuentran ahora cerrados" (Kranich, 2016, p. 109). Inclusive, ello ocurre con muchos contenidos online que actualmente están "restringidos, encapsulados y empaquetados" (Kranich, 2016, p. 109). Para explicar este fenómeno Kranich habla del cercamiento de los bienes comunes relacionados con el conocimiento y realiza un breve análisis histórico de cómo, a partir del último cuarto del siglo XX, comenzó un proceso creciente de apropiación de los mismos. Al respecto señala:

Se privatizó y clasificó la información del Estado, se fusionaron los editores de revistas y se modificaron las leyes de copyright como respuesta a la presión empresarial y los cambios en el discurso político, al ascenso de la economía global, la adopción de nuevas tecnologías y la facilidad de copiar archivos digitales. (Kranich, 2016, p. 108).

Para Kranich (2016) esta situación conspira contra el desarrollo de la investigación y la innovación, ya que para "que florezca el conocimiento, los investigadores siempre han necesitado del acceso libre y abierto a las ideas" (p.107).

Pero, este fenómeno de la privatización no se reduce al tipo de institución que gestiona la Educación Superior, sino que abarca también el problema de lo que Hoevel (2015) llama la "llegada de la business university", que básicamente consiste en la conversión de la universidad en una empresa. Hoevel asigna dos tipos de causas a este fenómeno. Por un lado, causas de tipo económico, una de las cuales es la globalización. Dado que si bien este modelo siempre existió (en muy pequeña escala), antes "el mercado estaba tan fuertemente regulado por el Estado que su presión sobre la Universidad era limitada" (Hoevel, 2015, p. 48). Pero cuando, de la mano de la globalización se desató la "feroz competencia en los mercados", resultó necesario aplicar a la universidad las mismas medidas de adaptación y ajuste que el resto de los actores de la economía. La globalización llevó a una mercantilización creciente de instituciones tradicionalmente no económicas, como los museos, las clínicas y hospitales, los clubes de fútbol y las de educación. 
Por otrolado, Hoevel argumenta la existencia de causas de tipo cultural. Según él, "en todas las épocas existió un ideal cultural y educativo que constituía el centro de las Universidades" (Hoevel, 2015, p. 49). En la Edad Media el objetivo de la Universidad fue la formación intelectual, en el Renacimiento lo fue la formación humanística y en el siglo XIX el foco estuvo puesto en la educación científica. Todas estas concepciones tenían un ideal objetivo para la universidad. Pero en la actualidad, para Hoevel no es posible encontrar una propuesta sobre cuál debe ser el ideal o valor para la educación. Por esa razón concluye: “Así, la debilidad de la Universidad frente al mercado no se debe solamente a la potencia que ha adquirido este último, sino a la debilidad de la cultura, al llamado 'pensamiento débil' que predomina en la Universidad" (Hoevel, 2015, p. 49). Esta derivación de las universidades privadas y públicas hacia empresas también ha sido señalada por Brunner y Miranda (2016).

Importa señalar que el debate sobre la privatización de la Educación Superior es reduccionista, en el sentido de que no diferencia, al interior de las instituciones privadas, entre las que tienen fines de lucro y las que no lo tienen. A esta última categoría pertenecen las universidades fundadas y gestionadas por órdenes religiosas y diversos tipos de asociaciones civiles. En particular, cabe recordar que las primeras universidades fueron creadas por diversas órdenes de la Iglesia Católica, y desde esos inicios hasta la actualidad, la razón de ser de las universidades católicas es contribuir a su misión evangelizadora más que generar ingresos económicos.

Así mismo, la Educación Superior de orden estatal delibera con respecto a su función principal -orientación teleológica- y la supervivencia en el "mercado", centrando el debate en la dicotomía existente entre el origen-destino tanto de los bienes públicos como de los bienes comunes en un marco de cogestión, por lo que vale la pena preguntarse, Educación Superior ¿Al servicio de quién? Y ¿para qué?

En síntesis, y tal como señala Unesco (2015), la “índole y el grado de participación privada en la educación está difuminando las fronteras entre educación pública y privada" (p. 84); y menciona tres ejemplos que lo ilustran: (a) la creciente dependencia de la financiación privada; (b) el incremento de instituciones de Educación Superior privada con o sin fines de lucro; (c) la introducción de métodos empresariales en la gestión.

\section{ALGUNOS DE LOS GRANDES PROBLEMAS DE LA EDUCACIÓN SUPERIOR EN LA ACTUALIDAD}

\section{El problema del financiamiento estatal}

Las tensiones surgidas entre los dos últimos congresos mundiales de Educación Superior de Unesco pusieron de manifiesto un cambio de foco hacia la latente preocupación por su financiación (Calderón, Vargas \& Pedro, 2011). Estamos asistiendo a una crisis en la capacidad 
de los Estados para hacer frente a un sistema de Educación Superior que requiere cada vez un volumen mayor de recursos financieros, en un contexto donde los Estados ven reducida su capacidad para aportar esos recursos. En ese sentido es que en el documento de Unesco (2015, p. 83) se señala: "la responsabilidad primera de los estados en la administración de la educación pública tropieza con una oposición cada vez mayor, con demandas de reducción del gasto público y una mayor participación de los agentes no estatales".

La expansión de las matrículas, la emergencia de nuevos campos de investigación y la creciente sofisticación de las tecnologías utilizadas en los procesos de investigación explican en buena medida la necesidad de mayores ingresos financieros. Pero también lo explican las dificultades para lograr eficiencias en el uso de los recursos o el tener que enfrentar nuevos costos, como es el caso de los precios que imponen las editoriales académicas que concentran la publicación de una parte importante de los journals. Con relación a esto último, Kranich indica:

A inicios de la década de 1990, las fusiones acaecidas en el sector de las editoriales académicas habían dejado que unos cuantos conglomerados internacionales tomaran el control del mismo, sobrecargando los ya ajustados presupuestos de las instituciones de educación superior por la imposición de tarifas de suscripción de hasta 20.000 dólares para revistas como Nuclear Physics, Brain Research y Tetrahedron Letters, que generaban beneficios de hasta el 40 por 100. (Kranich, 2016, p. 110)

Esta situación genera en las instituciones de Educación Superior públicas la necesidad de obtener nuevas fuentes de fondos, para lo cual deben recurrir al financiamiento del sector privado, ya sea por el lado del cobro de matrículas a los estudiantes (en algunos casos a través de becas financiadas por empresas y fundaciones privadas), como por el lado de la competencia por la obtención de fondos concursables, la construcción de alianzas con empresas privadas para desarrollar proyectos de investigación, de bienestar y extensión, así como la venta de servicios al sector corporativo. Como consecuencia de estas estrategias de supervivencia, se generan al menos dos nuevos problemas: se limita el acceso universal a estudiar en las universidades públicas y se comparte (o directamente, se subordina) con el sector corporativo la determinación del contenido de la agenda investigativa. De esta forma, el problema financiero corre el riesgo de devenir para las instituciones de Educación Superior en pérdida de soberanía.

Pero también, la dificultad creciente de los estados para financiar la Educación Superior acelera el proceso de privatización por la vía de crear espacios para el desarrollo de una oferta privada de educación e investigación. Lo más notorio consiste en la dificultad de las universidades estatales para responder a la demanda del mercado por nuevas profesiones, ya que a veces los Estados carecen de los fondos necesarios para financiarla, lo cual deja el camino abierto para el sector privado, quien se encarga de ofrecer las nuevas carreras profesionales. En el caso de la investigación, la reducción de los fondos provenientes del Estado limita los campos de actuación, acota las líneas de investigación y amplifica la fuga de científicos hacia el sector 
corporativo o hacia universidades con mayores recursos económicos (generalmente privadas), todo lo cual termina afectando negativamente la calidad y la pertinencia del conocimiento generado. Pero también, la reducción del financiamiento estimula en los investigadores comportamientos funcionales a los mecanismos de asignación de fondos (para viajes, contratar asistentes, etc.), que muchas veces van en detrimento de esa calidad y pertinencia. Todo esto genera oportunidades para las universidades privadas, muchas de las cuales poseen mayor flexibilidad y know how para encontrar fondos en el sector corporativo y en las diversas instituciones que financian la investigación.

De modo que las dificultades para obtener financiamiento de los Estados impulsa y dinamiza los procesos privatizadores en la Educación Superior por tres caminos convergentes: (a) mediante la creación de espacios para la oferta privada; (b) por un mayor grado de subordinación a los intereses del sector privado, tanto del mercado (en el caso de la oferta curricular) como de las empresas y fundaciones privadas que financian la investigación y (c) porque impulsa y legitima la adopción del modelo de gestión (y de universidad) propuesto por el Business University.

Es por todo lo anterior que Brunner y Pedraja (2017) señalan que la mercantilización de la Educación Superior no se refiere solamente al auge de las universidades privadas, sino que también involucra a las públicas, puesto que los sistemas de financiación de la educación están cambiando el mapa de universidades públicas tradicionales.

\section{Los problemas en la función educativa}

Es posible identificar al menos cinco problemas actuales de la Educación Superior en su función básica de educación: (a) su dificultad para ofrecer acceso y fortalecer la permanencia en condiciones de equidad a todos los sectores sociales; (b) problemas en su calidad; (c) creciente falta de pertinencia en su oferta de formaciones profesionales; (d) abandono de los componentes de formación humanística (principalmente los relacionados con la ética) en sus planes de estudio y (e) desarraigo de los vínculos e integración social.

El problema del acceso ya se observó como una de las primeras consecuencias de los procesos privatizadores. Desde el sigloXX existe un consenso mundial (al menos en Occidente) de que la educación es un derecho humano fundamental. Inclusive, en las sociedades occidentales la universalización de su acceso (en términos de crear igualdad de oportunidades para todos los ciudadanos) incrementó rápidamente sus objetivos, comenzando con la eliminación del analfabetismo, para luego aumentar progresivamente la apuesta a la obligatoriedad de culminar la Educación Primaria y más adelante la Secundaria, para llegar actualmente al acceso universal a la Educación Superior. No obstante ello, el logro de este último objetivo está siendo condicionado, principalmente debido a las dificultades crecientes de los Estados para financiar 
las universidades públicas, lo que reduce en forma paulatina la educación universitaria gratuita.

El problema de la calidad va de la mano de la masificación de la Educación Superior en un contexto de restricciones financieras. En ese sentido, Brunner y Miranda (2016) sostienen que debido a la masificación se ha generado que un número importante de docentes no reúnan los requisitos mínimos de posgrado o capacitación didáctica. A su vez, la masificación en algunas áreas de conocimiento ha provocado sobrecualificación del capital humano y desempleo. Un ejemplo interesante de esta situación atañe a la propia universidad. De la mano de las crecientes exigencias en algunos ratios que se utilizan para medir su calidad, las universidades (principalmente en los países desarrollados) han sobredimensionado la creación de programas de doctorado, muchas veces sin otro cometido que mejorar indicadores de desempeño. Como consecuencia de ello, se doctora gente que luego no consigue empleo como docente o investigador en las universidades o que, a lo sumo, obtiene empleos precarios o de bajos salarios, como es el caso de los "profesores asociados" en las universidades públicas o de los "contratos de obras o servicios" en las privadas. Una de las salidas para estas personas es la emigración hacia países con menos doctores, como es el caso de América Latina, con lo cual en sus países de origen se utilizaron recursos (claramente escasos) que luego no aplicaron sobre sus propias sociedades.

El tercer problema es el de la pertinencia de la oferta curricular. La reducción del financiamiento está afectando negativamente la capacidad de las universidades públicas para responder a las nuevas demandas de formación universitaria. Diversos estudios denuncian esta situación (Infosys, 2016; Knowledge@Wharton, 2016). Así, por ejemplo, en el informe The Future of Jobs Employment, Skills and Workforce Strategy for the Fourth Industrial Revolution. Global challenge inside report (World Economic Forum, 2016) se considera uno de los problemas más importantes que puede presentar este gap en un futuro de corto plazo: la llamada Cuarta Revolución Industrial. En el marco de esta revolución se generan entornos digitales en los cuales las máquinas se comunican con máquinas y nuevos productos suplen a los actuales para estar conectados a la red global de internet, exige la formación de nuevos perfiles profesionales en competencias tecnológicas para tener acceso a ese mismo mundo laboral (Organization Economic Cooperation Development, 2016).

Esta dificultad delas universidades públicas está siendoaprovechada por las universidades privadas, dado que por lo general interactúan más de cerca con el sector corporativo, más rápidamente identifican las nuevas necesidades del mercado y pueden definir los perfiles de competencias que demandan los cambios operados en este. Su mayor flexibilidad facilita el diseño de nuevas carreras profesionales y su relación con el sector corporativo hace lo propio con la inserción laboral de los nuevos egresados.

Finalmente, está el problema del retroceso en materia de formación humanística, en favor de la formación técnica. Señala Hoevel (2015): “la enseñanza de las ciencias, las artes y 
las profesiones ha ido cayendo en una mecanización, perdiendo su núcleo humanístico y su dimensión espiritual" (p. 49). En la misma línea, Unesco (2015) afirma: "Es importante insistir en que el giro reciente de la 'educación' hacia el 'aprendizaje' en el discurso internacional indica una posible falta de atención a las dimensiones colectivas y a la finalidad de la educación como tarea social" (p. 85).

En el contexto actual de tener que adaptarse a las demandas del mercado para obtener financiación, las universidades públicas y privadas están retirando contenidos y metodologías de formación humanística en favor de contenidos técnicos y de las metodologías que sirven para trasmitirlos. De esta manera se está descuidando el desarrollo de competencias morales, sociales y de conciencia ciudadana, lo cual redundará en profesionales maximizadores de sus intereses personales, con escasa conciencia de su responsabilidad social y ciudadana, todo lo cual limita las posibilidad de contar en el futuro con líderes comprometidos con un desarrollo inclusivo y sostenible, que es una de las grandes metas de la humanidad en los albores del siglo XXI.

\section{Los problemas en la función de investigación}

La enorme legitimidad que han alcanzado los sistemas de acreditación y los rankings internacionales viene de la mano de la competencia creciente entre las universidades por obtener fondos y captar estudiantes, principalmente de posgrado. Estos sistemas de acreditación, y particularmente las variables que se utilizan para construir los rankings de universidades, han generado (muy probablemente, sin proponérselo) un conjunto de estímulos para las instituciones y los académicos, de cuyas consecuencias negativas recién se está tomando conciencia.

Peter Lawrence (2008), prestigioso biólogo inglés, sostuvo que las métricas utilizadas para medir la producción científica se basan en lo accesorio (factores de impacto de las revistas, número de citas, etc.) y no en lo importante (los contenidos y los aportes de los trabajos publicados). Lo peligroso para Lawrence es que basándose en estas medidas se decide sobre temas relevantes como la obtención de una plaza (o la permanencia en ella) o el acceso a una beca de doctorado. En ese sentido Lawrence concluye:

...los científicos se han visto obligados a rebajar su objetivo primario de hacer descubrimientos a publicar tantos artículos como sea posible y tratar de publicarlos en revistas con factores de alto impacto. En consecuencia, el comportamiento científico se ha distorsionado y la utilidad, calidad y objetividad de los artículos se ha deteriorado. (Lawrence, 2008, p. 9).

Por su parte, Frey (2010) identifica tres fuerzas que socavan la academia: (a) la manía de los rankings; (b) la intensa presión que reciben los académicos por publicar, particularmente 
en revistas indexadas en determinados índices) y (c) el incremento de la mala conducta y el fraude. La primera está llevando a que el contenido de la investigación científica esté siendo determinado por indicadores externos a la propia universidad: "Hoy en día, en muchas disciplinas, la importancia de una idea científica y la posición de un erudito se definen por los rankings" (Frey, 2010, p. 2). La segunda está generando una importante distorsión en la producción académica, ya que los incentivos para publicar no van en línea con la creación de nuevos conocimientos valiosos y, en particular socavan la misión de la academia de perseguir el "conocimiento verdadero" (Frey, 2010). En el caso de la tercera (que es consecuencia de las dos anteriores) Frey sostiene que la causa principal de esta situación no radica en que "los eruditos sean menos morales que entonces solían ser", sino en que "los incentivos para engañar han aumentado mucho debido al mayor estrés en la academia". En 2002 Frey ya había sido contundente en su diagnóstico, al afirmar que la supervivencia de los investigadores dentro de las universidades depende fuertemente de publicar en revistas arbitradas por pares anónimos, lo que ha conducido a su prostitución intelectual, al ajustar los contenidos de sus artículos a las exigencias de los árbitros y editores de revistas científicas (Frey, 2002).

Esta situación fue analizada por Tsui (2015) para el caso particular de la producción académica de las escuelas de negocios. Tsui menciona tres consecuencias negativas de la creciente sumisión a las exigencias de los rankings y de la presión por publicar: (a) la existencia de una creciente brecha entre investigación y aplicación del conocimiento; (b) el fomento de prácticas de investigación moralmente cuestionables y (c) la homogenización de la investigación. La primera se explica porque la motivación principal de los académicos pasó de la producción de conocimiento útil para las empresas a obtener la aprobación de los editores y revisores de las revistas (Tsui, 2015). La segunda incluye prácticas como: "retener los detalles metodológicos, el informar selectivamente de los resultados, el uso de las ideas de otros investigadores sin darles reconocimiento y evitar observaciones con el fin de mejorar los resultados estadísticos e incluso la fabricación de resultados" (Tsui, 2015, p.19). Tsui también menciona la constitución de "comunas de publicación de artículos", que tienen como finalidad incrementar el número de artículos publicados por cada uno de sus integrantes. La tercera consecuencia deriva de la adopción de enfoques metodológicos, teorías y contenidos en función de las preferencias de los árbitros y de los editores de las revistas. Esto, a su vez, reduce el espacio para las nuevas ideas (Tsui, 2015).

Por su parte, Di Maggio (2016) analiza el impacto sobre la producción en el campo de las ciencias sociales: "Los doctorandos de ciencias sociales raramente son socializados por sus directores de tesis o sus tutores en la comprensión de la importancia de producir investigación que sea de utilidad en el mundo real" (p. 4). Y agrega que sus trabajos publicados "son totalmente ignorados por los políticos, porque están escritos en un lenguaje arcano y rebosante de jerga, jamás escrito pensando en lectores ajenos al ínfimo club de iniciados en la ciencia política" (Di 
Maggio, 2016, p. 5). Di Maggio también considera el problema de la mimetización de los enfoques metodológicos de las ciencias sociales con los que rigen en las ciencias "duras" y denuncia la obsesión de muchos politólogos por el empleo de sofisticadas herramientas matemáticas sin importar la relevancia cualitativa de los resultados publicados. Para ilustrar esta idea, transcribe algunos exóticos títulos de artículos que nada aportan al conocimiento de la ciencia política.

En el caso de las universidades latinoamericanas, la hegemonía de las agendas y metodologías de investigación impuestas por los editores de revistas académicas, así como los demás comportamientos disfuncionales derivados de la necesidad de cumplir con los requisitos de agencias de acreditación radicadas en los países desarrollados, constituyen, según Altbach (2016) un modelo neocolonialista de subyugar la producción de conocimientos a estándares y beneficios ajenos. En particular, esta situación desvía a las universidades latinoamericanas del cumplimiento de su responsabilidad social de contribuir a su territorio (Grau, Goddar, Hall, Hazelkorn \& Tandon, 2017).

En síntesis, la necesidad de las universidades de obtener buenos lugares en los rankings genera un conjunto de estímulos institucionales y personales que, a su vez, producen al menos los siguientes impactos negativos sobre su producción científica: (a) una brecha entre investigación y aplicación del conocimiento; (b) una agenda de investigación que responde más a la lógica interna de los sistemas de evaluación que a la búsqueda de respuestas a las necesidades de la sociedad (inclusive, de los financiadores) y (c) la propagación de prácticas inmorales que terminan afectando la calidad de la investigación.

\section{LOS BIENES COMUNES Y EL PROBLEMA DE SU GOBERNANZA Los bienes comunes}

La expresión "bienes comunes" (commons, en inglés) fue creada para analizar la problemática emergente de la sostenibilidad en el uso de algunos recursos naturales (agua, aire, etc.), pero con el tiempo comenzó a emplearse para referirse a un conjunto más amplio de bienes, entre los que se incluyen diversos servicios que permiten satisfacer derechos humanos básicos. Así por ejemplo, Barlow (2008) señala que muchas sociedades modernas ampliaron este concepto, abarcando lo que se denomina "ámbitos comunes sociales", entre los que se incluye la salud, la educación o la seguridad social.

La aplicación del término commons a diferentes problemáticas, y su abordaje desde distintas perspectivas, ha complejizado su conceptualización, al punto de que el Foro Mundial sobre Globalización propuso la existencia de tres tipos de bienes comunes: (1) el conjunto de recursos naturales de los cuales depende la vida de la humanidad (ejemplo: el agua, los bosques, las reservas de peces, el aire, la capa de ozono, etc.); (2) las creaciones colectivas de la humanidad (ejemplo: la cultura y el conocimiento) y (3) los bienes sociales (aquellos que 
garantizan el acceso universal a la salud, la educación y la seguridad social) (Gutiérrez \& Mora, 2011). En línea con esto último, Subirats (2011) propone:

Estaríamos refiriéndonos a bienes, recursos, que más allá de la propiedad o la pertenencia, asumen, por su propia vocación natural y económica, funciones de interés social, sirviendo directamente los intereses, no de las administraciones públicas, sino los de la colectividad y de las personas que la componen. (p. 196)

De lo anterior es fácil deducir que actualmente se trata de un concepto en construcción. Gutiérrez y Mora (2011) identifican tres tipos de definiciones, categorizadas en función de la forma como en ellas se concibe a los commons: (a) únicamente como recursos; (b) como una relación social (entre el recurso y la comunidad) y (c) como una relación política. En este tercer tipo de definiciones se incluyen las propuestas políticas relacionadas con la gobernanza de los bienes comunes. Sobre esta tercera categoría, estos autores incluyen la siguiente definición:

Commons se entiende como concepto que da sentido y dirección a una propuesta política y que nos sitúa en tres temas esenciales: (1) el acceso a recursos y bienes que conforman nuestro patrimonio social, natural y cultural; (2) el proceso de producción y reproducción social tanto de bienes comunes como del bien común y (3) la distribución equitativa en la repartición de los beneficios que emergen de nuestro acervo común. (Gutiérrez \& Mora, 2011, p. 132).

Mientras que los bienes privados son de propiedad individual (de una persona o una organización) y los bienes públicos son posesión del Estado, los bienes comunes son propiedad de la comunidad. Por esa razón, en tanto que el derecho al uso de los bienes privados queda legitimado por su adquisición en el mercado y el derecho al uso de los bienes públicos lo está por el hecho de ser ciudadano (y, en algunos casos, pagar algún tipo de canon como el peaje para circular en una carretera.), los bienes comunes son utilizados sin tener que pagar ningún precio (ello pasa con el aire que respiramos, el agua de los mares, los paisajes naturales, etc.). Dicho de otro modo, los bienes comunes son aquellos sobre los cuales todas las personas tienen derecho de uso por el simple hecho de ser parte de la humanidad o de una comunidad concreta. Es en este sentido que Unesco (2015) los define como "aquellos que, independientemente de cualquier origen público o privado, se caracterizan por un destino obligatorio y necesario para la realización de los derechos fundamentales de todas las personas" (p. 85).

Más aún, tal como lo señala Subirats (2011), en el caso de los bienes comunes no se puede hablar de un tipo específico de propiedad, sino de lo opuesto a la propiedad, y concluye:

Lo común no es mercantilizable (trasmisible, enajenable) y no puede ser objeto de posesión individualizada...No 'tenemos' un bien común, formamos parte de lo común, en la medida que formamos parte de un ecosistema, de un conjunto de relaciones en un entorno...y por tanto el sujeto forma parte del objeto. Los bienes comunes están inseparablemente unidos y unen a las personas, las comunidades y el propio ecosistema. (Subirats, 2011, p. 197). 
Según Barlow (2008), en "los últimos años se han realizado avances importantes en la generación de una conciencia renovada del antiguo concepto de 'bienes comunes'" (p. 3). Sin embargo, existe confusión entre bienes públicos y comunes, dado que ambos comparten la característica del acceso universal; es decir, la no exclusión de nadie con respecto a su uso o consumo. Sin embargo, mientras que el consumo de los primeros es independiente entre usuarios (es decir, no hay rivalidad entre ellos), en los bienes comunes las ventajas obtenidas por unos pueden ir en desmedro de las de otros e, inclusive, negarles el acceso. Así, por ejemplo, mientras que la utilidad obtenida por el usuario de una carretera (bien público) no afecta la que obtienen los demás usuarios, en el caso del agua o el aire (bienes comunes), el uso abusivo de unos limita el acceso de otros, tanto de las nuevas como de las futuras generaciones. También, así como ningún ciudadano puede apropiarse de las plazas y parques de su ciudad, en cambio algunos actores pueden hacerlo con bienes comunes sociales como el conocimiento y la educación, poniendo límites a su acceso universal. En el caso del conocimiento académico, para leer papers publicados por determinadas revistas es necesario pagar, y no todos los investigadores pueden hacerlo. Y, en el caso de la educación, en algunos países hasta las universidades públicas cobran para estudiar en ellas.

En ese sentido, Zamagni (2014) apunta que la dificultad todavía existente para conceptualizar correctamente la noción de bienes comunes radica, entre otras razones, en la confusión habitual entre este tipo de bienes y los públicos. En ese sentido señala:

El bien común, en cambio, es un bien rival en el consumo, pero no exclusivo, y además es aquel en que la utilidad que cada uno obtiene de su uso no puede ser separada de la utilidad que otras personas obtienen de ella. Sería como decir que el beneficio que el individuo obtiene del bien común se materializa junto al de los otros, y no en contra o prescindiendo de los otros. (Zamagni, 2014, p. 26).

Así, por ejemplo, en el caso de la Educación Superior, esta confusión ha llevado a la idea bastante generalizada de que el Estado es el actor más adecuado para gestionarla.

De lo último transcripto más arriba de Zamagni se infiere una de las características específicas de este tipo de bienes: su uso depende de la existencia de relaciones de reciprocidad entre los usuarios. En ese sentido, Sánchez Enríquez (2014) sostiene que los bienes comunes se producen y obtienen mediante relaciones entre personas y grupos y, por tanto, "son un producto de relaciones interactuantes" (p. 3). De ahí que este tipo de bienes "no existen fuera de nuestras relaciones. Más aún, como indica Zamagni (2014), "el beneficio que un individuo extrae de un bien común se materializa junto al de los demás y no en contra ni prescindiendo de los demás" (p. 27). De allí que algunos autores sostienen que los bienes comunes no son otra cosa sino una relación social.

Otra característica interesante de los bienes comunes es su transgeneracionalidad (Figueroa, 2016), en el sentido de que pertenecen tanto a las generaciones actuales como a 
las futuras, a la comunidad actual y a la futura. Sobre esta idea se apoya actualmente la idea del uso sostenible de los recursos medioambientales. Esta característica, para Figueroa (2016) “implica que no pueden ser gestionados en términos de racionalidad individual ni tener como objetivos las 'ganancias'"' (p. 1).

Importa señalar que el concepto de bienes comunes no coincide con el de Bien Común, ya que ambos aluden a fenómenos distintos, tal como lo señala Subirats (2011), para quien: "No estamos hablando de una cuestión moral (el Bien Común), sino de sistemas concretos de gestión y de mantenimiento de recursos sociales y ambientales" (p.198). Mientras que los bienes comunes son entidades concretas (tangibles o intangibles), el Bien Común "es el bien propio de la vida en común y de las relaciones significativas entre las personas" (Zamagni, 2007, p. 23); es decir, una cuestión moral, un valor universal. Luego de mencionar varios bienes comunes (belleza, paz, arte, cultura, libertad, etc.), Argandoña (2011) afirma: “Todos estos puedes ser ‘bienes comunes', que concretan de algún modo, el concepto abstracto y trascendente del bien común, pero que no lo agotan" (p. 5).

Tampoco, el Bien Común equivale al llamado "interés general" porque, como indica Zamagni (2007), "es el bien de las personas que viven y que se constituyen en sociedad" y no el "bien indistinto de la sociedad" (p. 24). O, como señala Argandoña (2011), "por ser común no puede ser el bien de algunos, ni siquiera de la mayoría, sino el bien de todos y cada uno de ellos, al mismo tiempo" (p. 3). En línea con esta idea, la Doctrina Social de la Iglesia, uno de cuyos cuatro principios es el Bien Común, indica que éste no consiste en la "simple suma de los bienes particulares de cada sujeto del cuerpo social. Siendo de todos y de cada uno es y permanece común, porque es indivisible y porque solo juntos es posible alcanzarlo, acrecentarlo y custodiarlo (Pontificio Consejo de Justicia y Paz, 2005).

En síntesis, los bienes comunes no coinciden con el Bien Común ni con el interés general, pero lo que sí ocurre es que su gobernanza y uso requieren contemplar el interés general y contribuir al Bien Común.

A modo de síntesis, es posible señalar algunas características específicas de este tipo de bienes: (a) son de acceso universal, es decir, todos los miembros de la comunidad poseen el derecho de acceder a ellos; (b) el uso que hacen unos miembros de la comunidad puede afectar negativamente el acceso de otros; (c) son de propiedad comunitaria (ni estatal ni privada), lo cual significa que quienes los "poseen" en realidad no son sus propietarios y, por lo tanto, su uso debe ser funcional con su naturaleza; $(d)$ son bienes relacionales $\mathrm{y}$, por lo tanto, se producen y usan en el marco de relaciones entre personas y grupos; (e) son transgeneracionales, es decir, su producción y consumo requieren garantías de sustentabilidad y (f) su uso requiere contemplar el interés general y contribuir al Bien Común.

Importa señalar, finalmente, que esta identidad específica delos bienes comunes requiere: (a) formas de gobernanza que aseguren que su producción, reproducción, distribución, acceso 
y consumo no vayan en contra de esa identidad, y (b) que la comunidad a la que pertenecen esté involucrada en su gobernanza.

\section{La tragedia de los bienes comunes}

El biólogo evolucionista norteamericano Hardin (1968) sostuvo que los bienes comunes están condenados a ser saqueados y agotados por no existir un propietario que se interese por preservarlos. Dicho de otro modo, la ausencia de un propietario (actor privado o estatal) deja sin garantías la accesibilidad y sostenibilidad de este tipo de bienes. Para fundamentar esta afirmación, Hardin recurre a la metáfora del campo de pastoreo comunitario, donde cada pastor lleva a pastar sus animales. Según este autor, si algunos pastores procuran maximizar su utilidad aumentando el número de animales, el consumo de hierba (bien común) superará el máximo que el sistema soporta para regenerarse y, en consecuencia, se verá amenazada su sustentabilidad. La única forma de que esto no ocurra consiste en que otros pastores renuncien a su derecho a utilizar el campo de pastoreo, con lo cual queda amenazada la accesibilidad. A este problema se le conoce como la "tragedia de los comunes".

El razonamiento de Hardin permite explicar la actual crisis medioambiental, que está conduciendo a la destrucción de los bienes comunes naturales, pero también aplica a los otros dos tipos de bienes comunes propuestos por el Foro Mundial sobre la Globalización: las creaciones colectivas de la humanidad (entre los que se encuentra el conocimiento) y los bienes sociales (la educación, por ejemplo), aunque en ambos casos el drama de los commons se manifiesta de otra forma. En este caso no se trata de su destrucción, porque todos ellos se pueden renovar ya que son creaciones humanas. Aquí el problema consiste en la exclusión a su acceso y por lo tanto su negación como bienes comunes. A pesar de que nadie discute en nuestras sociedades que la educación y la salud son derechos universales, aún no hemos encontrado la forma de garantizar el acceso universal a las mismas. De igual forma, en la base de la discusión sobre el software libre (Bollier, 2008) está el problema del acceso al conocimiento, que también hoy es considerado un bien común.

Predominan dos enfoques para enfrentar la tragedia de los comunes. Por un lado está la solución privatizadora propuesta por Hardin (1968), que se basa en la premisa de que el mecanismo del mercado asegura la asignación óptima de los recursos comunes. El problema aquí radica en que este mecanismo requiere que exista libertad para vender y para comprar. Pero la realidad es que existe una asimetría entre vendedores y compradores, ya que no todos los individuos poseen los recursos para comprar, es decir, no tienen la libertad para hacerlo. Inclusive, tal como advierte Zamagni (2014), esto ocurre porque los "bienes (o servicios) indispensables para la supervivencia no tienen sustitutos más o menos perfectos" (p. 31). Esta situación conduce a la exclusión en el acceso de quienes no pueden pagar el costo. Piénsese, 
por ejemplo, en el caso del acceso a las carreras universitarias por quienes no pueden pagar la matrícula o del acceso de los investigadores a publicaciones académicas que requieren el pago de un precio por ellas. En ambos casos no hay bienes sustitutos y, por lo tanto, quienes no puedan pagar su precio quedarán excluidos de acceder a ellos. Considérese además, que si el propietario del bien prioriza maximizar su utilidad, la situación es más grave aún.

Por otro lado está la solución estatizadora, mediante la conversión del bien común en público, la cual tiene varios problemas. Zamagni (2014) identifica dos de estos problemas. El primero es el del financiamiento, ya que los Estados tienen capacidad limitada de recursos económicos, en un contexto global donde se multiplican las demandas de diversos actores y los problemas por resolver. Los Estados del siglo XXI cada vez tienen menos capacidad para solventar los costos de asegurar derechos fundamentales, como la alimentación, la salud, la educación y la seguridad social.

El segundo problema es el que Zamagni (2014) denomina “fallas del gobierno", entre las que destacan la burocracia y la búsqueda de renta (rent seeking). La burocracia es una falla derivada, principalmente, de lo que se llama "problema de agencia" (Jensen \& Meckling, 1976), que en este caso ocurre cuando el agente (persona que administra el Estado) prioriza su interés personal o corporativo por sobre el del propietario (la comunidad de ciudadanos). Así, por ejemplo, la calidad de la educación y de la producción de conocimiento se ven afectados por el nepotismo, la búsqueda personal de prestigio o las múltiples estrategias que docentes e investigadores desarrollan para sortear reglas de juego que dificultan sus carreras profesionales.

La búsqueda de renta consiste en la manipulación delos recursos del Estado con la finalidad de obtener beneficios individuales o corporativos. Según Pasour (1987) el término rent seeking se utiliza para describir los intentos de obtener y mantener transferencias de riqueza desde el Estado hacia individuos u organizaciones, incluyendo una amplia gama de actividades, entre las que se encuentran las exoneraciones fiscales, las demandas sindicales, los aranceles y las cuotas de importación, la asignación de fondos para proyectos de investigación y los subsidios a la educación. Para Buchanan (2008) este tipo de comportamientos de individuos y grupos, orientados a maximizar la apropiación de valor, "generan desgaste social más que excedente social" (p. 56). Por esa razón, Pasour afirma que:

...el aumento de los grupos de presión especializados es un factor clave en la disminución de la tasa de crecimiento económico de las naciones, lo que se suma a la crítica de este fenómeno generalizado en el que los grupos organizados utilizan el poder del Estado para promover sus propios fines económicos. (Pasour, 1987, p. 123).

La corrupción es la forma extrema en que se manifiestan el problema de agencia y el de la búsqueda de renta.

Ante esta dificultad (o imposibilidad) de los sistemas privados y públicos para resolver el problema de la "tragedia de los comunes", diversos autores sostienen que el camino es la 
solución comunitaria. Ostrom (1990), quien recibiera el premio Nobel de Economía en 2009 por sus aportes en este campo, propuso la necesidad de encontrar modelos específicos de gestión comunitaria para los bienes comunes y habló de "cooperación organizada". Por su parte, Zamagni (2014) afirma que la solución comunitaria es la que ofrece mayores posibilidades para superar la tragedia de los comunes, destacando el papel de la fraternidad en este tipo de solución:

Sin el reconocimiento del valor del vínculo, que es algo distinto del valor de uso y del valor de cambio, no se sale de la tragedia de los commons. Para los bienes comunes no basta la mano invisible del mercado, ni tampoco es suficiente la mano visible del Estado. Es necesario, por el contrario, una economía de los bienes comunes que esté anclada en el principio de fraternidad. (Zamagni, 2014, p. 35).

Sánchez Enríquez (2014) afirma que la tragedia de los bienes comunes es, en realidad, la tragedia de sus usuarios y que, por lo tanto, la solución pasa por la creación de formas de cooperación entre ellos que estén basadas en relaciones de reciprocidad. Al respecto, sostiene:

La forma de cooperación más efectiva sería aquella que permita el uso eficaz del bien común basado en el compromiso interactivo, permanente, que beneficia de manera equitativa al conjunto de usuarios a la vez que asegura la sostenibilidad del recurso. Esta modalidad de uso sería caracterizada mediante la idea de las relaciones de reciprocidad entre el conjunto de usuarios. (Sánchez Enríquez, 2014, p. 2).

De igual forma Gutiérrez y Mora (2011) sostienen que: "El grito por los bienes comunes es un grito por un nuevo espíritu de comunidad, por anteponer el interés del bien común al mercado" (p. 135).

\section{La gobernanza de los bienes comunes y la Responsabilidad Social.}

De lo anterior, y tal como diversos autores lo sugieren, los bienes comunes requieren de mecanismos degobernanza específicos. El aporte más importante en este sentidolo hizo Ostrom (1990), quien propuso que la gobernanza de los bienes comunes tiene que ser consistente con la naturaleza de este tipo de bienes $\mathrm{y}$, por lo tanto, requiere el involucramiento directo de la comunidad que tiene derecho sobre ellos. O, como dice Zamagni (2014): "si este bien es común, también su gestión debe serlo" (p. 33). Esto tiene algunas implicancias importantes. Esto equivale a decir que la gestión de los bienes comunes debe estar en manos de los grupos de interés directamente relacionados con su producción y acceso; o al menos, escuchar su voz y contemplar sus intereses.

Más aún, tal como sostiene Subirats (2011), se ha demostrado la necesidad "de estructuras o instituciones que puedan gestionar los bienes comunes, reforzar las interdependencias y disuadir a los que quieran aprovecharse de los mismos de manera oportunista" (p. 199). En particular, estas instituciones tienen que permitir un mayor control democrático (Gutiérrez \& 
Mora, 2011) por parte de los integrantes de la comunidad, a efectos de minimizar la emergencia de los mismos problemas que afectan al modelo de gestión pública: el de agencia y el de búsqueda de renta.

En la misma línea de pensamiento, Sánchez Enríquez (2014) señala que el acceso y uso de los bienes comunes requiere el "cumplimiento de contratos y acuerdos explícitos o implícitos" (p. 3) y que fuera de estos contratos y acuerdos los bienes comunes "simplemente no existen y pasan a ser uno de los otros dos tipos mencionados (privados y públicos)" (p. 3).

Ostrom (1990) propuso un conjunto de principios basados en el diseño de sistemas de gobierno adecuados para los bienes comunes. Subirats (2011) y Landoni (2016) mencionan algunos de ellos: (1) delimitar claramente a quienes incluye; (2) contar con un marco de funcionamiento que establezca las reglas para su producción y acceso; (3) establecer métodos de toma de decisión colectivas que incorporen las voces de todos los involucrados; (4) contar con mecanismos de monitoreo y gestión en los que ellos participen; (5) existencia de sanciones para quienes incumplen (en particular, los free riders); (6) contar con mecanismos que favorezcan una buena resolución de los conflictos; (7) el reconocimiento y legitimidad otorgados por terceros a esta forma de organización y (8) crear entidades anidadas que organizan la participación de los múltiples actores involucrados.

Ahora bien, dado que la casi totalidad de los bienes comunes son actualmente gestionados por el Estado o por empresas privadas, parece poco razonable proponer su sustitución por instituciones comunitarias u organizaciones del Tercer Sector, como las Organizaciones No Gubernamentales (ONG), las fundaciones u otros tipos de asociaciones civiles. Por otra parte, este tipo de instituciones tampoco es inmune a los problemas que aquejan al sector privado y al Estado, ya que para funcionar tienen que crear estructuras burocráticas que son igualmente vulnerables al problema de agencia, la rent seeking y el accionar de los free riders.

Esta es la razón por la cual la solución del problema no pasa por modificar el tipo de propiedad de las organizaciones que gestionan los bienes comunes, sino por hacerlo con la forma como se los gestiona; es decir, se requiere un cambio de paradigma que pase de enfocar el asunto en la propiedad para hacerlo en la gobernanza. O dicho de otro modo, comprender que la solución no pasa por el quién posee y gestiona (organización estatal, privada o del Tercer Sector) sino por el cómo se lo hace (la gobernanza).

En ese sentido, el ya consolidado concepto de Responsabilidad Social delas Organizaciones (RSO), tal comofueformulado en la guía ISO26.000 (UNIT, 2011), aporta un modelo de gobernanza para todo tipo de organizaciones, que es especialmente válido para aquellas que gestionan bienes comunes. Esta guía define la RSO como "la responsabilidad de una organización ante los impactos que sus decisiones y actividades ocasionan en la sociedad y el medioambiente, mediante un comportamiento ético y transparente" (UNIT, 2011, p. 18). Además, propone que esta responsabilidad implica tomar en cuenta las expectativas de todos los stakeholders, 
contribuir al desarrollo sostenible y estar integrada en toda la organización. La guía ISO 26.000 establece que la RSO requiere modificar las formas actuales de gobernanza de las organizaciones y aporta un marco conceptual y orientaciones prácticas para su diseño e implementación. Este marco conceptual incluye un conjunto de principios, entre los cuales destacan la incorporación de la ética, la transparencia y la rendición de cuentas y el requisito de incorporar los intereses de los stakeholders, incluyendo a las generaciones futuras (UNIT, 2011), todo lo cual va en línea con los principios de la gobernanza de los bienes comunes propuestos por Ostrom.

En suma, se entiende aquí que la RSO es una solución alternativa a la dificultad inherente a los distintos tipos de organizaciones actualmente existentes para asegurar la correcta gestión de los bienes comunes. O, como sugiere Zamagni (2005), al asumir que en la sociedad actual no existen "instituciones civiles y justas" orientadas al Bien Común: "Esta es la razón por la cual es socialmente responsable aquella empresa que contribuye a definir una ética cívica que sepa construir formas de condensación organizativa de las cuales puedan emerger instituciones civiles justas" (p. 34).

\section{La educación superior como bien común}

¿Por qué proponer a la Educación Superior como un bien común, si actualmente se trata de un bien gestionado por el Estado (bien público) o por distintas instituciones de carácter privado (bien privado)? Hablar de bien común implica además discutir los fines mismos de la educación superior y sus aspectos teleológicos. Educación superior centrada en el ¿bien Ser? O ¿el bien tener?

Hay en primer lugar un argumento ontológico, ya que la Educación Superior cumple con las características identitarias de los bienes comunes descritas en este documento y, por lo tanto, es un bien común: (a) el acceso a la formación profesional y al conocimiento científico debe ser universal en nuestras sociedades modernas; (b) tal como se observó en el primer apartado, la forma como se comportan algunos miembros de la comunidad afecta el acceso de otros (es el caso de los costos y barreras al acceso a determinadas publicaciones o el cobro de matrículas como consecuencia de mantener ineficiencias, incapacidad o desidia); (c) aunque sea gestionada por instituciones públicas o privadas, para cumplir sus fines la Educación Superior necesita incorporar las voces de todos los actores involucrados (estudiantes, empleadores, financiadores, usuarios del conocimiento producido, Estado, egresados, etc.), con lo cual no es propiedad de ninguna de esas instituciones, sino de la comunidad en la que operan; (d) son bienes relacionales, porque la educación y la investigación son esencialmente acciones sociales que involucran la cooperación y la reciprocidad entre los actores que participan de ellas; (e) son transgeneracionales, ya que involucran también fuertemente a las generaciones futuras (los profesionales formados y el conocimiento producido tienen un 
importante impacto en el futuro); y (f) claramente, su producción, distribución y consumo deben considerar el interés general (por ejemplo, el bienestar que en la sociedad pueden generar el conocimiento científico y los buenos profesionales) y el Bien Común (en tanto y cuanto involucra la formación de profesionales orientados hacia él).

Este argumento ontológico está avalado por el hecho de que hace ya tiempo que la teoría (o teorías) de los bienes comunes incluye el conocimiento y la educación en su decálogo de bienes comunes (Gutiérrez \& Mora, 2011; Subirats, 2011). Ambos entran dentro de lo que Marlowe et al. (2008) denominan "ámbitos comunes sociales". También ya se mencionó que el Foro Mundial sobre la Globalización ubica el conocimiento entre los bienes comunes llamados "creaciones colectivas de nuestra especie" y a la educación entre los "bienes comunes sociales". De esta forma, el fuerte desarrollo teórico sobre este concepto seguramente aporta un marco de teoría para encontrar solución a los problemas de la Educación Superior que son propios de los bienes comunes, como es el caso de asegurar su acceso universal y su sostenibilidad.

Así, por ejemplo, la obra colectiva titulada "Los bienes comunes del conocimiento", cuya publicación en 2007 fue coordinada por Hess y Ostrom, aporta las bases de un marco conceptual para analizar los problemas actuales de la producción, distribución y acceso a la información y al conocimiento. Hess y Ostrom señalan que crece el número de investigadores académicos que encuentran en el concepto de bienes comunes un marco teórico adecuado para analizar los nuevos dilemas asociados a la distribución de la información digital, "que estaba siendo vallada, mercantilizada y sobrepatentada" (Hess \& Ostrom, 2016, p. 28). En este marco se habla de bienes comunes digitales, electrónicos, de información, virtuales, de comunicación, intelectuales, tecnológicos, etc., para abordar el problema actual de la “información global distribuida” (Hess \& Ostrom, 2016, p. 28).

Pero además, hay argumentos de orden fáctico. El argumento central de Unesco tiene la intención de poner freno a los crecientes procesos de privatización que sufre la Educación Superior. Pero existe una razón más profunda, a saber: la teoría sobre los bienes comunes aporta un nuevo marco conceptual para analizar los grandes problemas que tiene actualmente la Educación Superior y encontrar soluciones a los mismos. Detrás de la propuesta de Unesco está el doble convencimiento de que, por un lado, la conceptualización de la Educación Superior como bien público no permite encontrar la solución al problema de su creciente privatización y, por otro, que migrar a considerarla como un bien común puede servir para encontrarla. Unesco se da cuenta de la necesidad de cambiar el paradigma (que concibe la Educación Superior como bien público), ya que de no hacerlo la única alternativa a la privatización sería la vuelta a la gestión pública, ya sea en forma directa (universidades públicas) o mediante nuevas formas de tercerización que la convierten en un bien de propiedad pública y gestión privada. 


\section{La educación superior como un bien común y la solución a sus problemas actuales}

Un breve repaso a los problemas de la Educación Superior descritos en el primer apartado muestra claramente que si la educación y la producción deconocimiento fueran efectivamente gestionadas como bienes comunes, dichos problemas no existirían o tendrían una relevancia mucho menor.

Esto es así porque: (a) el cobro de matrículas y las diversas formas de cercamiento del conocimiento producido (derechos deautor, cobrode papersacadémicos, patentes, etc.) atentan contra el acceso universal; (b) las prácticas deshonestas de estudiantes y académicos afectan la calidad del trabajo de sus colegas; (c) la convicción de los egresados universitarios de que los conocimientos adquiridos son propios, para su propio beneficio y no para el de la sociedad, así como la apropiación del conocimiento científico por los grupos corporativos que lo financian o por las editoriales que lo difunden, desnaturalizan el sentido de propiedad comunitaria que tienen la educación y la producción de conocimiento; (d) los métodos de enseñanza inspirados en el Business University y la falta de estímulos a la creación de auténticas redes de cooperación entre académicos (mayormente preocupados por cumplir con las exigencias derivadas de la necesidad de las universidades por figurar en los rankings) destruyen la relacionalidad humana inherente a los bienes comunes; (e) la falta de pertinencia de la oferta de carreras profesionales, el abandono de los componentes de formación humanística, la creciente brecha entre investigación y aplicación del conocimiento y la homogeneización de la investigación atentan contra su sostenibilidad intergeneracional y, finalmente, (f) todo lo anterior, lejos de contribuir al interés general y al Bien Común, apunta en sentido contrario.

En general, los autores e instituciones que insisten en posicionar la Educación Superior como un bien público lo hacen como forma de frenar los procesos que llevan a la apropiación privada del conocimiento (García Menéndez, 2009; Pusser, 2005), bajo la hipótesis correcta de que dicha apropiación es la causa principal de muchos de esos problemas. Pero lo que estos autores no se dan cuenta, es que la gestión de la Educación Superior bajo los modelos de gobernanza de los bienes públicos tampoco puede impedirlos, por las mismas razones que ello ocurre para los bienes comunes en general debido, entre otros, al problema de agencia y a la búsqueda de renta, propios del gobierno estatal. Son manifestaciones del problema de agencia las estrategias adoptadas por los investigadores para adaptarse a las exigencias del sistema, tanto las claramente inmorales como las que no lo son. Pero también lo son las decisiones de los administradores que, en un marco de restricciones presupuestarias, en vez de generar eficiencias (lo que en algunos casos requiere renunciar a privilegios establecidos) optan por reducir la oferta de formaciones profesionales y adoptan agendas de investigación impuestas por los agentes que la financian. Es una manifestación de la rent seeking la imposición de costos por actores externos, como ocurre con los grupos editoriales que manejan los índices más reconocidos. 
Ahora bien, si se consideran con atención todos estos problemas, se encuentra que tienen en común el hecho de ser una manifestación de la tragedia de los bienes comunes: el uso abusivo y egoísta de unos usuarios afecta negativamente el de otros. En función de lo analizado en el segundo apartado, la solución general a esta tragedia no pasa por modificar la naturaleza del actor que gestiona el bien común, sino que consiste en establecer mecanismos específicos para su gobernanza, diferentes a los tradicionales del sector privado y del estado, como los basados en los principios propuestos por Ostrom.

Si bien estos principios son aplicables a las universidades, resulta necesario releerlos e interpretarlos a la realidad específica de los bienes comunes que gestionan estas instituciones. Este proceso ofrece diferentes grados de dificultad según el principio del que se trate. En algunos casos la dificultad parece ser menor (por ejemplo, el principio que establece la obligatoriedad de delimitar con claridad a quienes incluye el bien común), pero en otros la dificultad puede alcanzar dimensiones superlativas, ya que los intereses en juego son seguramente relevantes para los actores involucrados (por ejemplo, es muy difícil obtener consensos para determinar las sanciones para quienes actúan mal).

Por otra parte, la aplicación de la mayoría de esos principios requiere un rediseño institucional que, además de afectar intereses particulares, supone dificultades operativas y cambios culturales profundos para estas instituciones. Este es el caso de principio que propone contar con métodos de toma de decisiones colectivas que incorporen la voz de todos los stakeholders involucrados, ya que existen dificultades prácticas para incorporar en la toma de decisiones a algunos de ellos, como por ejemplo a los empleadores, las empresas que utilizan el conocimiento científico producido por las universidades, las organizaciones de la comunidad o los padres de los estudiantes. Pero además, las resistencias culturales al cambio y a la pérdida de posiciones de poder seguramente serán muy elevadas, aún en modelos de gobernanza universitaria en los que existen mecanismos de cogestión de académicos, estudiantes y egresados, como es el caso de algunas universidades estatales luego de la reforma de Córdoba. En efecto, en estas universidades se observa un proceso de "privatización", que ocurre no en el sentido de la apropiación capitalista, sino en el de que esos actores tienden a gestionarlas en beneficio de sus propios intereses corporativos, lo cual constituye también una forma de apropiarse de este bien común.

\section{El rol de la Responsabilidad Social Universitaria}

Dado que actualmente la absoluta mayoría de las universidades son de gestión estatal o privada resulta utópico e irresponsable proponer que pasen a ser gestionadas por las comunidades a las que proveen de conocimiento y educación, tal como sugiere la teoría de los bienes comunes. Sin embargo, se entiende aquí que ambos tipos de universidades podrían incorporar 
en sus modelos de gobernanza elementos propios de la gobernanza de los bienes comunes (en particular, los principios propuestos por Ostrom). Al igual que para el conjunto de bienes comunes, la solución pasaría por la incorporación a su gobernanza de las orientaciones teóricas y metodológicas de la Responsabilidad Social Universitaria (RSU), manifestación específica de la RSO que, tal como señala Vallaeys (2014), no es "una mera aplicación a la universidad de los procesos de responsabilidad social empresarial, puesto que los impactos universitarios son genuinos y se cuidan desde las genuinas competencias académicas de la universidad" (p. 108). Y, en la misma línea, señala el principal documento de la red AUSJAL (2009) sobre RSU: "no se trata de incorporar mecánicamente en las universidades el concepto de Responsabilidad Social desarrollado en el ámbito de la empresa...sino de reinventar este concepto desde la especificidad de la labor universitaria" (p.11).

Además de las empresas, las universidades son el único tipo de organizaciones que han desarrollado un cuerpo de teoría y metodologías para la aplicación práctica de su responsabilidad social, pudiendo observarse a nivel de Iberoamérica "dos formas de entender el concepto y su aplicación" (Martí-Noguera \& Martí-Vilar, 2013, p. 148). El primero, originado en América Latina, pone fuerte foco en el trabajo con la comunidad y en la importancia de formar ciudadanos conscientes de la realidad socioeconómica de sus países. En cambio, el segundo, promovido en España, focaliza en aspectos relacionados con los modelos de gestión, "cuya realización está en línea con modelos empresariales de reporte organizacional a la sociedad" (Martí-Noguera \& Martí-Vilar, 2013, p. 148).

En América Latina, el desarrollo conceptual de la RSU se inició durante el primer lustro del siglo XXI con el trabajo colectivo de una red de universidades chilenas denominada Universidad Construye País (UCP) y con el aporte del programa Red Universitaria de Ética y Desarrollo Social (RUEDS), impulsada por el Banco Interamericano de Desarrollo (BID). Este último se basó en una serie de documentos elaborados por Vallaeys y Carrizo (2006), quienes, antes de la publicación de la guía ISO 26.000, propusieron un concepto de RSU basado en la idea de la gestión responsable de los impactos de la actividad universitaria, enfatizando en los impactos de sus tres funciones básicas (educación, investigación y extensión), además de los impactos organizativos comunes a todo tipo de organizaciones (Vallaeys, s/f; Vallaeys, 2014).

Posteriormente, se registraron avances interesantes en países como Colombia y Perú, pero probablemente el marco conceptual y metodológico con mayor complejidad sea el que elaboró AUSJAL (red de universidades latinoamericanas gestionadas por los padres jesuitas), considerado por Martí-Noguera y Martí-Vilar (2013) "una evolución que recoge los trabajos desarrollados por el proyecto UCP y el BID” (p. 152). En el documento "Políticas y sistema de autoevaluación y gestión de la Responsabilidad Social Universitaria en AUSJAL" se sostiene que las tres funciones básicas de la universidad "deben estar animadas por la búsqueda de la promoción de la justicia, la solidaridad, la equidad social, mediante la construcción 
de respuestas exitosas para atender los retos que implica promover el desarrollo humano sustentable (AUSJAL, 2009).

El movimiento intelectual que está detrás de la creación del concepto de RSU plantea un cuestionamiento y un replanteo del rol de la universidad, exigiéndole asumir un mayor compromiso de naturaleza ética con la realidad particular de cada sociedad (Licandro, Fernandez \& Marturet, 2013). Así, por ejemplo, en la definición de RSU propuesta en el proyecto Universidad Construye País, se enfatiza en la idea de asociar este concepto con "la capacidad que tiene la universidad de difundir y poner en práctica un conjunto de principios y valores generales y específicos" (Zurita, 2003, p. 65). O, tal como lo señala Vallaeys, la RSU exige, desde una visión holística, articular las diversas partes de la institución en un proyecto de promoción social de principios éticos y de desarrollo social y equitativo y sostenible, para la producción y trasmisión de saberes responsables y la formación de profesionales ciudadanos, igualmente responsables. (Vallaeys, s/f, p. 4).

El "core" del concepto de RSU predominante en América Latina, basado en la propuestas iniciales de UCP y de la RUEDS, está claramente alineado con una conceptualización de la Educación Superior como un bien común, cuya producción, distribución y uso debe estar orientado al Bien Común. En particular, proporciona orientaciones para gestionar las funciones de educación y producción de conocimiento como bienes comunes. A modo de ejemplo, cabe mencionar algunas de las políticas que propone AUSJAL para estas dos funciones.

En el caso de la función educativa, el documento propone, entre otras cosas, orientar el currículo para acercarloala “realidad del país ylaregión”, ofrecer alos estudiantes “oportunidades vivenciales de acercamiento a la realidad social y de servicio", desarrollar un "liderazgo basado en la democracia participativa" y "una clara conciencia de las implicaciones éticas de su actuación personal y profesional" (AUSJAL, 2009, p. 22). También se incluye como política el "facilitar el acceso y permanencia en la universidad de personas con dificultades económicas" (AUSJAL, 2009, p. 24), llegando inclusive a proponer esto para otros segmentos vulnerables como las personas con discapacidad. Para la función investigación el documento propone "definir una agenda temática de investigación que privilegie la realidad latinoamericana" (AUSJAL, 2009, p. 23), generar espacios interdisciplinarios y desarrollar redes, y "divulgar la producción académica haciéndola accesible y comprensible a la comunidad, actores sociales relevantes y decisores políticos" (AUSJAL, 2009, p. 23). De aquí se infiere que las universidades de AUSJAL, al menos en su discurso, se proponen abordar los problemas antes señalados por los que atraviesa la Educación Superior en materia de formación e investigación.

Finalmente, importa destacar una situación emergente que resulta peligrosa para la consolidación de la RSU y que, en consecuencia, seguramente limitará su capacidad para contribuir al desarrollo de modelos de gobernanza para la Educación Superior que sean consistentes con su naturaleza de bien común. Tal como lo demuestra el trabajo de Martí, 
Calderón y Fernández (2018), en algunos países de Iberoamérica (los autores estudian los casos de Perú, Brasil y España) se está legislando sobre la RSU, lo cual atenta contra un componente central del concepto de RSO tal como este ha sido consensuado en la guía ISO 26.000 (UNIT, 2011): su voluntariedad. En efecto, al legislar sobre RSU se "obliga al establecimiento de un modelo o sistema que permita homogeneidad en su implementación, metodología y reportes, de forma que el Estado pueda verificar los alcances acometidos por las IES en cumplimento de la ley" (Martí et al., 2018, p. 109).

Esta situación, aunque en forma aparente constituye un avance positivo para la aplicación de la RSU, implica una paradoja, ya que la Responsabilidad Social no refiere al cumplimiento de las leyes o los contratos, sino a comportamientos voluntarios libremente adoptados por las organizaciones para reducir los impactos negativos de su operación o para generar impactos positivos sobre sus stakeholders (Licandro, 2016). Todo lo incluido en la legislación bajo el rótulo de RSU deja automáticamente de considerarse RSU, para pasar a formar parte del cuerpo de normas que impone la sociedad a la universidad. Este avance de la legislación involucra dos grandes peligros. Por un lado, se corre el riesgo de vaciar de contenido a la RSU y, por otro, puede implicar un retroceso hacia una conceptualización de la Educación Superior como bien público.

Por lo tanto, esta conceptualización requiere, como condición necesaria, que más quelegislar sobre el tema, los Estados se focalicen en crear estímulos y generar condiciones que favorezcan la incorporación voluntaria de la RSU (por ejemplo, impulsar mecanismos de acreditación de títulos que incluyan estándares de RSU o direccionar fondos en función del cumplimiento de este tipo de estándares), tal como ya se ha argumentado para el sector corporativo (Licandro, 2016). Importa señalar que aquí no se sugiere la idea de que los Estados no deben legislar sobre la Educación Superior, lo que se afirma es que no deben hacerlo sobre la RSU.

\section{COMENTARIOS FINALES}

Al igual que ocurre con otros llamados de la Organización de Naciones Unidas (ONU) en temas tan diversos como la paz, el desarrollo o la infancia, el que hizo Unesco en 2015 para cambiar el paradigma sobre la naturaleza de la Educación Superior, pasando de conceptualizarla como un bien público a hacerlo como un bien común, corre el riesgo de quedar en la buena intención y en el discurso. De ahí la necesidad de comenzar a reflexionar sobre las implicancias teóricas y prácticas de esta re-conceptualización de la Educación Superior, a efectos de diseñar estrategias que permitan hacer efectivo ese llamado.

En este artículo se argumenta que la propuesta de Unesco es correcta desde el punto de vista ontológico, porque la Educación Superior y sus productos (la formación y el conocimiento) responden a la definición de bienes comunes (commons) y que, además, su aplicación permitiría encontrar respuestas a los grandes problemas por los que atraviesa actualmente la Educación 
Superior. Se señala además, que la incorporación en las universidades de mecanismos de gobernanza típicos de este tipo de bienes es un camino realista antela imposibilidad de convertir las universidades estatales y privadas en instituciones gobernadas directamente por las comunidades involucradas, tal como lo exige la naturaleza de los bienes comunes. Finalmente, se sugiere aquí que la teoría sobre la Responsabilidad Social Universitaria aporta un marco conceptual y práctico para gestionar las universidades como bienes comunes orientados al interés general y al Bien Común.

La tarea es gigante y exige enfrentar múltiples desafíos, entre los que destacan por su importancia: (a) convencer a los líderes de todos los sectores involucrados, particularmente el liderazgo político (que es quien orienta y canaliza las demandas de los ciudadanos) sobre la necesidad de cambiar el rumbo; (b) desarrollar conciencia y compromiso en todos los stakeholder involucrados de forma más o menos directa en los procesos de producción, distribución y uso de los productos de la Educación Superior (administradores, académicos, estudiantes, agentes financiadores, etc.); (c) identificar y sustituir todos los estímulos actuales que llevan en la práctica a que esos actores actúen como si la formación y la producción de conocimiento fueran bienes privatizables de los que apoderarse, aunque ello genere la exclusión de otros usuarios; (d) enfrentar con inteligencia y firmeza los obstáculos que pondrán los actores beneficiados por el actual statu quo; y (e) establecer una agenda de debate que conduzca a propuestas concretas para el diseño de mecanismos de gobernanza congruentes con la idea de Educación Superior como bien común y que sean aplicables tanto en instituciones estatales como privadas.

Finalmente, se entiende necesario insistir en la idea de que el concepto de Responsabilidad Social Universitaria, que ya cuenta con un interesante desarrollo teórico y metodológico, es consistente con la idea de Educación Superior como bien común y que, por lo tanto, no es necesario partir de cero. Se puede comenzar traduciendo sus principios y orientaciones en clave de bienes comunes. 


\section{REFERENCIAS}

Altbach, P. G. (2016). Global perspectives in higher Education. Baltimore: Johns Hopkins University Press.

Argandoña, A. (2011). El Bien Común (Documento de Investigación 937). Navarra: IESE Business School, Universidad de Navarra. Recuperado de https://goo.gl/6i7adk

AUSJAL (2009). Políticas y sistema de autoevaluación y gestión de la Responsabilidad Social Universitaria en AUSJAL. Córdoba: Red de RSU de AUSJAL.

Barlow, M. (2008). El Agua Nuestro Bien Común: hacia una nueva narrativa del agua. México: Oficina Regional para México, Centroamérica y Caribe de la Fundación Heinrich Böll Stiftung. Recuperado de https://goo.gl/AIfcg5

Bollier, D. (2008). Viral spiral: how the commoners built a digital republic of their own. New York: The New Press.

Brunner, J. J. \& Miranda, D. A. (Eds.). (2016). Educación Superior en Iberoamérica. Informe 2016. Chile: Centro Interuniversitario de Desarrollo - CINDA. Recuperdo de https://goo.gl/ZLKetl

Brunner, J. J. \& Pedraja, L. (2017). Los desafíos de la gobernanza de la educación superior en Iberoamérica Ingeniare Revista chilena de ingeniería, 25(1), 2-4. doi: http://dx.doi.org/10.4067/S0718-33052017000100002

Buchanan, J. M. (2008). Rent Seeking and Profit Seeking. En R. Congleton, A. Hillman, \& K. Konrad (Eds.), 40 years of Research on Rent Seeking 1: Theory of Rent Seeking (pp. 55-68). New York: Springer.

Calderón, A. I., Vargas, M. C \& Pedro, R. F. (2011). Responsabilidade social da Educação Superior: a metamorfose do discurso da UNESCO em foco. Interface (Botucatu), 15(39), 1185-1198. doi: http://dx.doi.org/10.1590/S1414-32832011000400017

Di Maggio, A. (2014). Sobre la cobardía y la irrelevancia de la ciencia social académica. Recuperado de https://goo.gl/Ljg5ks

Figueroa, M (2016) La educación y el conocimiento: ¿un bien común? Parte 1. Recuperado de https://goo.gl/No2RNY

Frey, B. (2002). Publishing as Prostitution? Choosing Between One's Own Ideas and Academic Failure. Zurich IEER Working Paper, 117. doi: http://dx.doi.org/10.2139/ssrn.316699

Frey, B. (2010). Withering Academia? CESifo Working Paper Series, $N^{\circ} 3209$. Recuperado de https://goo.gl/oDAVk9

García Menéndez, J. R. (octubre 2009). La mercantilización de la educación superior: ¿Bien público o negocio privado? Trabajo presentado en la II Jornadas de Economía Crítica, Bahía Blanca, Argentina. Recuperado de https://goo.gl/gpYXdD

Grau, F. X., Goddard, J., Hall, B. L., Hazelkorn, E. \& Tandon, R. (Eds.). (2017). Higher education in the world: Vol. 6. Towards a socially responsible university: Balancing the global with the local. Girona, España: Global Univeristy Network for Innovation. Recuperado de https://goo.gl/cgc2a7

Gutiérrez, A. L. \& Mora, F. (2011). El grito de los bienes comunes: ¿qué son y qué nos aportan? Revista de Ciencias Sociales Universidad de Costa Rica. , 1-2(131-132), 127-145. Recuperado de https://goo.gl/AUAu6H

Hardin, G. (1968). The Tragedy of de Commons. Science, 162(3859), 1243-1248. doi: http://dx.doi.org/10.1126/science.162.3859.1243

Hess, C \& Ostrom, E. (2016). Los bienes comunes del conocimiento. Quito: Instituto de Altos Estudios del Ecuador.

Hoevel, C. (2015). Ante la llegada de la business university. Revista Integra Educativa, 8(2), 44-62. Recuperado de https://goo.gl/cZfrjS Infosys (2016). Amplifying human potential: education and skills for the fourth industrial revolution. Recuperado de https://goo.gl/ XiWIIJ

Jensen, M. C. \& Meckling, W. H. (1976): Theory of the Firm: Managerial Behaviour, Agency Cost and Ownership Structure. Journal of Financial Economics, 3(4), 305-360. doi: https://doi.org/10.1016/0304-405X(76)90026-X

Knowledge@Wharton (febrero 2016). College vs. Business Training: What Do Employers Want? Recuperado de https://goo.gl/itzAC3 Kranich, N. (2016). Para contrarrestar el cercamiento, recuperar los bienes comunes del conocimiento. En C. Hess, \& E. Ostrom, (Eds). Los bienes comunes del conocimiento, (pp. 107-142). Quito: Instituto de Altos Estudios del Ecuador.

Landoni, J. S. (2016). Elinor Ostrom y el gobierno de los recursos de uso común, en una primera aproximación y el problema de la naturaleza humana. Libertas Segunda Época, 1(1), 173-195. Recuperado de https://goo.gl/hZUkp1

Lawrence, P. (2008). Lost in publication: how measurement harms science. Ethics in Science and Environmental Politics, 8(1), 9-11. doi: https://doi.org/10.3354/esep00079

Licandro, O. (2016). Responsabilidad Social Empresaria. Reflexiones, investigaciones y casos de estudio. Montevideo: Grupo Magro. Recuperado de https://goo.gl/hwoMuu

Licandro, O., Fernández, M. \& Marturet, M. (2011). La formación de profesionales responsables: el caso de la Facultad de Odontología de la Universidad Católica del Uruguay. Cuadernos de RSO, 1, 58-72.

Marlowe, F. W., Berbesque, J. C., Barr, A., Barrett, C., Bolyanatz, A. Cardenas, J. C. ... Tracer, D. (2008). More 'altruistic' punishment in larger societies, Proceedings of the Royal Society B, 275(1634), 587-592. doi: https://doi.org/10.1098/rspb.2007.1517 
Martí-Noguera, J. J., Calderón A. I. \& Fernández-Godenzi, A. (2018). La responsabilidad social universitaria en Iberoamérica: Análisis de las legislaciones de Brasil, España y Perú. Revista Iberoamericana de Educación Superior, 9(24), 107-124. doi: http://dx.doi. org/10.22201/iisue.20072872e.2018.24.264

Martí-Noguera, J. J. \& Martí-Vilar, M. (2013). Una década de Responsabilidad Social Universitaria en Iberoamérica. Revista española del Tercer Sector, 25, 145-161. Recuperado de https://goo.gl/zZKuqi

Organization Economic Cooperation Development (2016). Education at a Glance 2016: OECD Indicators. Paris: OECD Publishing. Recuperado de https://goo.gl/VnPXay

Ostrom, E. (1990). Governing the Commons: The Evolution of Institutions for Collective Action. New York: Cambridge University Press.

Pasour, E. C. (1987). Rent Seeking: Some Conceptual Problems and Implications. The Review of Austrian Economics, 1(1), 123-143. doi: https://doi.org/10.1007/BF01539337

Pontificio Consejo Justicia y Paz (2005), Compendio de Doctrina Social de la Iglesia. Montevideo: Librería Editorial Arquidiocesana.

Pusser, B. (2005) Educación Superior, el mercado emergente y el bien público: Cuadernos del Seminario de Educación Superior de la UNAM, $N^{\circ}$ 2. México: SES, UNAM. Recuperado de https://goo.gl/9DHY6q

Sánchez Enríquez, R. (setiembre 2014). Bienes comunes y Bien Común. ¿Las raíces relegadas de la gestión democrática? Trabajo presentado en el Seminario Internacional. 18 y 19 de setiembre de 2014, Lima-Perú.

Subirats, J. (2011). Algunos apuntes sobre la relación entre los bienes comunes y la economía social y solidaria. Otra Economía, 5(9), 195-2004. Recuperado de https://goo.gl/a7RGi8

Tsui, A. (2015). Reconectando con el mundo del negocio. Investigación socialmente responsable. EFMD Global Focus, Edición en Castellano, 18-22. Recuperado de https://goo.gl/iEVuaW

Unesco (2015). Replantear la educación. ¿Hacia un bien común mundial? Paris: Autor. Recuperado de https://goo.gl/GcXwuk

UNIT (2011). Guía de Responsabilidad Social (ISO 26.000: 2012, IDT). Montevideo: Autor.

Vallaeys, F. (2014). La responsabilidad social universitaria: un nuevo modelo universitario contra la mercantilización. Revista Iberoamericana de Educación Superior, 5(12), 105-117. Recuperado de https://goo.gl/aF8XK4

Vallaeys, F. (s/f) ¿Qué es la Responsabilidad Social Universitaria? Recuperado de https://goo.gl/3yGKZp

Vallaeys, F \& Carrizo, L. (2006). Responsabilidad social universitaria: marco conceptual, antecedentes, herramientas. Lima: Banco Interamericano de Desarrollo.

World Economic Forum (2016). The Future of Jobs Employment, Skills and Workforce Strategy for the Fourth Industrial Revolution. Global challenge inside report. Geneva: WEF. Recuperado de https://goo.gl/g7QWRJ

Zamagni, S. (2005). El fundamento ético de la Responsabilidad Social de la Empresa. Universitas. Revista de Sociedad y Cultura de la Pontificia Universidad Católica Argentina, 1(1), 27-42.

Zamagni, S. (2007). El Bien Común en la sociedad postmoderna: propuestas para la acción político-económica. Cultura Económica 70, 23-43. Recuperado de https://goo.gl/52aL57

Zamagni, S. (2014). Bienes comunes y bien común. En O. Groppa, \& C. Hoevel (Eds). Economía del don. Perspectivas para Latinoamérica (pp. 25-46). Buenos Aires: Ciudad Nueva.

Zurita, R (2003) Rol de las universidades. En Universidad Construye País (eds). Educando para la Responsabilidad Social. Santiago: Autor, 61-67.

RIDU / Revista Digital de Investigación en Docencia Universitaria / ISNN 2223-2516

(c) Los autores. Este artículo es publicado por la Revista Digital de Investigación en Docencia Universitaria del Área de Institutional Research and Effectiveness de la Dirección de Aseguramiento de la Calidad, Universidad Peruana de Ciencias Aplicadas. Este es un artículo de acceso abierto, distribuido bajo los términos de la LicenciaCreativeCommons Atribución-CompartirIgual 4.0 Internacional ( http://creativecommons.org/licenses/by-sa/4.0/), que permite el uso no comercial, distribución y reproducción en cualquier medio, siempre que la obra original sea debidamente citada. 